\title{
PELATIHAN PEMBUATAN WEB SEBAGAI MEDIA INFORMASI, PUBLIKASI DAN PROMOSI BAGI SISWA SMK BINA INSAN
}

\author{
Syahril*, Doni Winarso, Risnal Diansyah, Edo Arribe, Aryanto \\ Prodi Sistem Informasi, Fakultas Ilmu Komputer \\ Universitas Muhammadiyah Riau \\ email: syahril@umri.ac.id
}

\begin{abstract}
The website at the beginning of its discovery was used only as a means to exchange information between researchers, but now it has developed into a medium for disseminating information used by almost all fields of life. This community service aims to provide understanding and skills to Bina Insan Vocational School (SMK) students about website technology and how to build websites as a means to disseminate information, publicize and make it as a media campaign. This service method uses project and workshop methods. The number of participants who took part in this activity were 25 students of Bina Insan Vocational School consisting of 15 students from the Department of Software Engineering (RPL) and 10 people from the Department of Computer Engineering (TKJ). This activity was also attended by 2 student teacher assistants. The results of community service are in the form of students' abilities or skills in building a website. Measurement of success is done by looking at the results of the project examples that were given to participants. Of the 20 participants, 17 of them managed to make and complete a simple website that can be used as a medium to convey information, publications and promotions and be ready to upload to internet hosting.
\end{abstract}

Keywords: Media Information, SMK Bina Insan, Websiite.

\begin{abstract}
Abstrak
Website pada awal penemuannya digunakan hanya sebagai sarana untuk bertukar informasi antar peneliti, namun saat ini sudah berkembang menjadi media penyebaran informasi yang digunakan oleh hampir semua bidang kehidupan. Pengabdian masyarakat ini bertujuan untuk memberikan pemahaman dan skill kepada siswa Sekolah Menengah Kejuruan (SMK) Bina Insan tentang teknologi website dan bagaimana membangun website sebagai sarana untuk menyebarkan informasi, publikasi dan menjadikan sebagai media promosi. Metode pengabdian ini menggunakan metode proyek dan workshop. Jumlah peserta yang mengikuti kegiatan ini sebanyak 25 orang siswa SMK Bina Insan yang terdiri dari 15 siswa berasal dari jurusan Rekayasa Perangkat Lunak(RPL) dan 10 orang dari jurusan Teknik Komputer Jaringan(TKJ). Kegiatan ini juga diikuti oleh 2 orang guru pendamping siswa. Hasil dari pengabdian kepada Masyarakat ini berupa kemampuan atau skill siswa dalam membangun sebuah website. Pengukuran keberhasilan dilakukan dengan melihat hasil contoh proyek yang di berikan kepada peserta. Dari 20 peserta 17 diantaranya berhasil membuat dan menyelesaikan website sederhana yang dapat dijadikan media untuk menyampaikan informasi, publikasi dan promosi serta siap untuk diupload kehosting internet.
\end{abstract}

Kata Kunci: Media Informasi, SMK Bina Insan, Websiite.

\section{PENDAHULUAN}

Perkembangan teknologi internet membawa perubahan yang sangat besar terhadap kehidupan manusia disegala bidang. Bahkan teknologi informasi telah berhasil mengubah beberapa cara seseorang maupun organisasi dalam menjalankan aktivitas sehari-harinya, terlebih setelah terbukanya jaringan global dunia yang menghubungkan antar komputer satu dengan komputer lainnya atau disebut dengan internet [1]. Jaringan ini telah 
sukses mengubah cara berkomunikasi, mengekspresikan diri, atau mengubah cara memasarkan sebuah produk dalam dunia perdagangan.

Perkembangan teknologi internet semakin pesat seiring ditemukanya web browser oleh tim berners lee, sehingga akses data berupa gambar dan audio visual dapat dinikmati dengan mudah menggunakan teknologi ini[2]. Sampai saat ini tercatat ada sekitar lebih dari 1.6 miliar situs website yang berada di internet[3]. Dari sekian miliar website yang ada tercatat yang aktif hingga september 2018 sebanyak 183 juta lebih. Web tersebut terdiri dari portal berita, company profile, online shop dan blog.

Senada dengan data di atas netcraft[4] berdasarkan survei yang mereka lakukan dan dirilis dilaman websitenya, jumlah website yang ada senantiasa terus meningkat dari tahun ketahun. Tercatat di tahun 1995 jumlah website hanya sekitar 10 ribu meningkat tajam hingga tahun 2018 berjumlah sekitar 163 miliar namadomain yang terdaftar diseluruh dunia. Data tersebut disajikan pada diagram berikut

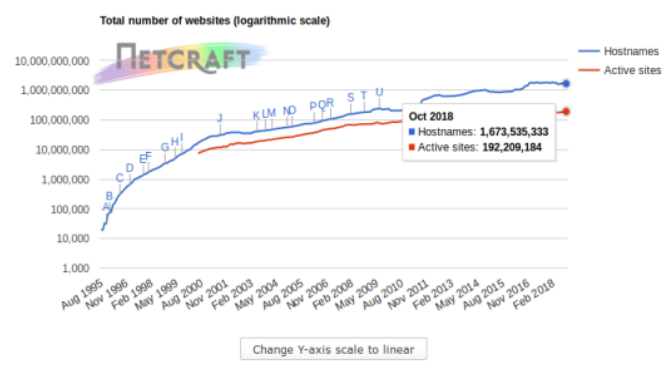

Gambar 1. Data Jumlah Website Dunia

Pemanfaatan website sebagai sarana penyebaran informasi dan publikasi menjadi pilihan yang banyak diambil sebagai solusi, karena media ini memiliki kelebihan yang dapat menjangkau pengguna internet dimanapun berada dan kapanpun ingin mengaksesnya. Selain itu website juga merupakan sarana dengan biaya murah untuk mempromosikan suatu produk dan jasa. Namun tidak semua orang dapat membangun dan membuat website dengan tujuan sebagaimana dijelaskan diatas. Perlu keahlian dan keterampilan khusus untuk dapat menghasilkan sebuah website yang baik dan user friendly.

Kehalian dalam membangun sebuah website bisa didapatkan melalui kelaskelas kursus dan training yang dilaksanakan oleh suatu lembaga keahlian. Namun tentunya kursus dan training ini membutuhkan biaya yang tinggi. Berangkat dari hal tersebut dosen program studi sistem informasi Fakultas Ilmu Komputer Universitas Muhammadiyah Riau tergerak untuk melaksanakan pengabdian dengan cara memberikan pelatihan pembuatan website kepada siswa SMK Bina Insan. Alasan dipilihnya siswa dan siswi SMK Bina Insan dalam pengabdian ini adalah karena usia dan masa remaja siswa dan siswi ini tentunya memiliki semangat yang tinggi untuk mempelajari teknologi. pengabdian ini juga sebagai sarana mempersiapkan generasi yang melek akan teknologi website dimasa akan datang.

\section{METODE PENELITIAN}

Khalayak sasaran dalam kegiatan ini adalah siswa SMK BINA INSAN yang berada di kabupaten Kampar. Jumlah siswa yang terlibat dalam kegiatan ini sebanyak 25 orang, dengan memiliki dasar pengetahuan web. Karena ini merupakan program keahlian maka yang diutamakan adalah siswa yang berminat mengembangkan web.

Metode yang digunakan dalam kegiatan pengabdian ini adalah proyek, membuat web, dan workshop. Materi yang disampaikan meliputi Pengantar dan Perkembangan pembuatan web, Hingga mengupload ke hosting sebuah web yang berada di internet. 
Kegiatan pengabdian ini dilaksanakan pada bulan september 2018 bertempat di Laboratorium SMK Bina Insan. Rancangan jadwal kegiatan dapat dilihat pada tabel berikut ini.

Tabel 1. Jadwal Kegiatan

\begin{tabular}{|c|c|c|c|}
\hline \multirow{2}{*}{ No } & \multirow{2}{*}{ Kegiatan } & \multicolumn{2}{|c|}{ Bulan } \\
\hline & & Agustus & September \\
\hline 1 & 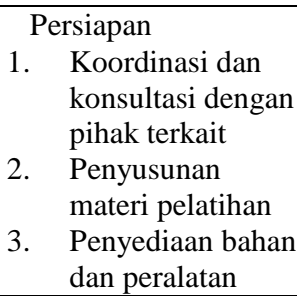 & & \\
\hline 2 & $\begin{array}{l}\text { Pelaksanaan } \\
\text { 1. Penyampaian } \\
\text { materimelalui } \\
\text { pelatihan dan } \\
\text { diskusi } \\
\text { 2. Diskusi dan Tanya } \\
\text { Jawab }\end{array}$ & & \\
\hline 3 & $\begin{array}{l}\text { Laporan } \\
\text { 1. Pembuatan draft } \\
\text { laporan } \\
\text { 2. Penyusunan dan } \\
\text { perbanyakan } \\
\text { laporan }\end{array}$ & & \\
\hline
\end{tabular}

\section{HASIL DAN PEMBAHASAN}

Pelaksanaan kegiatan diawali dengan pembukaan yang dilakukan oleh pihak sekolah SMK Bina Insan. Hadir dalam kegitan pengabdian bapak Budi Arham, M.Kom selaku kepala sekolah yang sekaligus membuka kegiatan pengabdian ini.

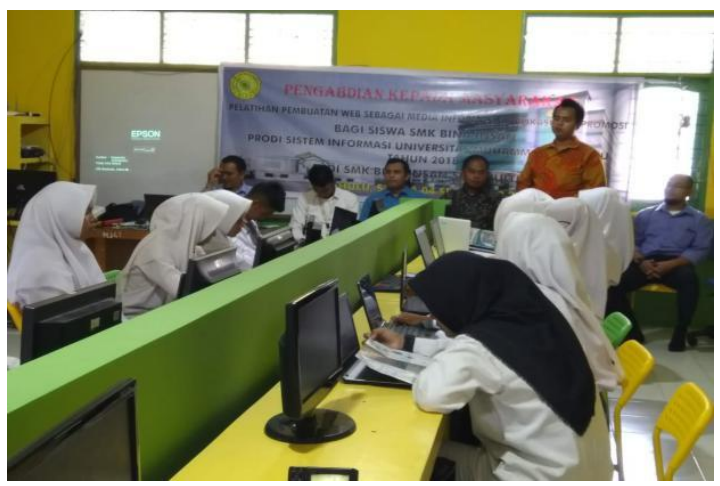

Gambar 2 Pembukaan Oleh Kepala Sekolah
Kegiatan diikuti oleh 25 orang siswa dan 2 orang guru pembimbing. Kegiatan tersebut mendapatkan antusias yang tinggi dari para peserta. Hal ini karena materi yang disampaikan merupakan materi yang mereka butuhkan untuk dapat melatih skill pemrograman berbasis web. Terlihat antusias terkait materi Hyper Text Markup Language (HTML) yang disajikan oleh Edo Arribe, MMSI

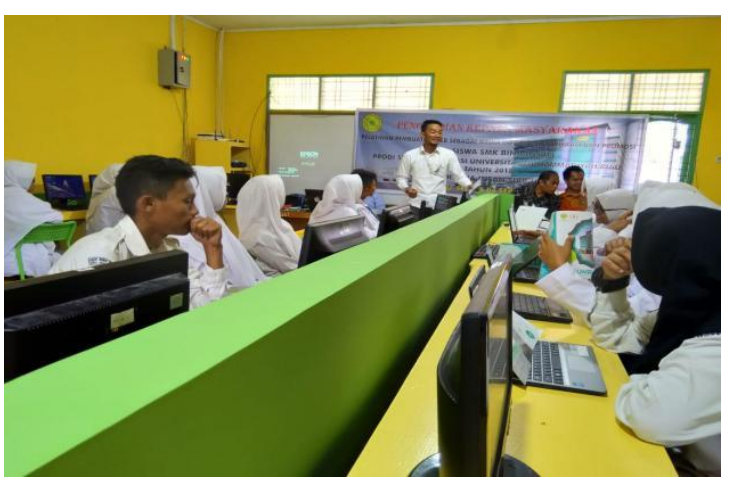

Gambar 3. Penyampaian Materi HTML

Materi utama disajikan oleh Syahril, M.Kom, Risnal Diansyah, MTI, Doni Winarso, M.Kom dan Aryanto SE, MIT.Ak berupa pengenalan dasar sampai tingkat menengah terkait materi cascade Style Sheet (CSS), bahasa pemrograman PHP, Java Script sampai kepada bagaimana mendapatkan nama domain dan upload web ke hosting di internet.

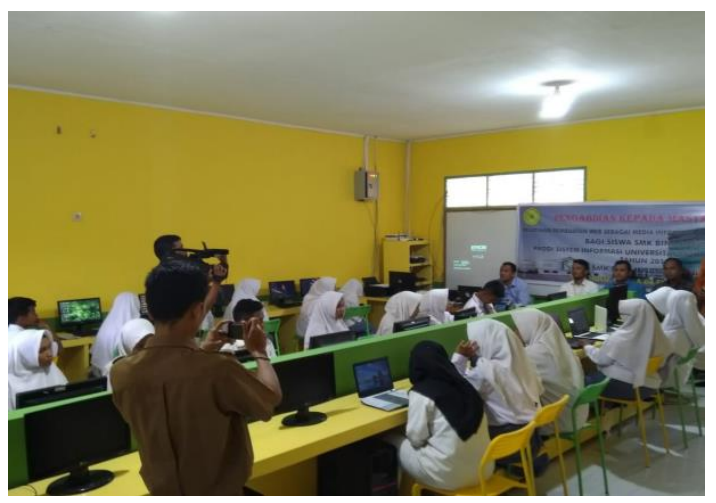

Gambar 4. Penyajian Materi Utama

Kegiatan pengabdian yang dilakukan mendapat antusias yang tinggi dari peserta dan pelaksanaannya dinyatakan berhasil dan telah sukses. Hal ini dapat diukur melalui proyek yang diberikan 
kepada peserta. Dari 25 siswa yang mengikuti pelatihan 18 diantaranya berhasil menyelesaikan proyek berupa website sederhana yang bisa dipublish di server internet. Pelatihan ini juga memberikan meteri tentang bagaimana mengupload website ke server yang ada diinternet dan bagaimana cara pembelian nama domain dan sewa hosting. Berikut salah satu hasil proyek yang dibuat oleh siswa yang mengikuti kegiatan pengabdian ini.

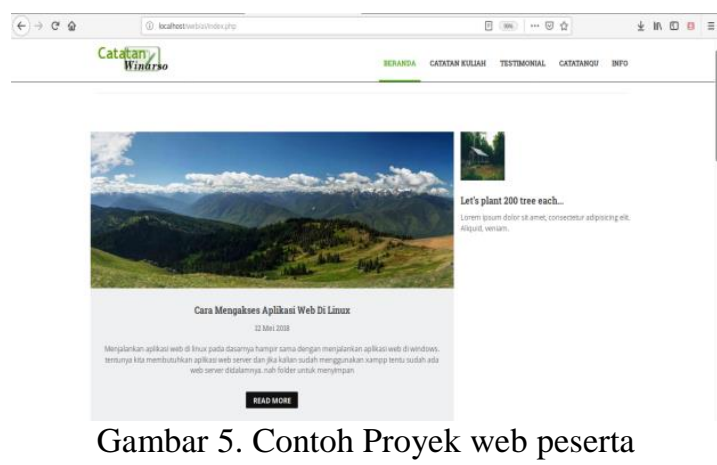

Diakhir kegiatan pengabdian ini ditutup oleh sedikit arahan dari dekan Fakultas Ilmu Komputer bapak Aryanto SE, MIT.Ak. Dan foto bersama seluruh pemateri dan peserta.

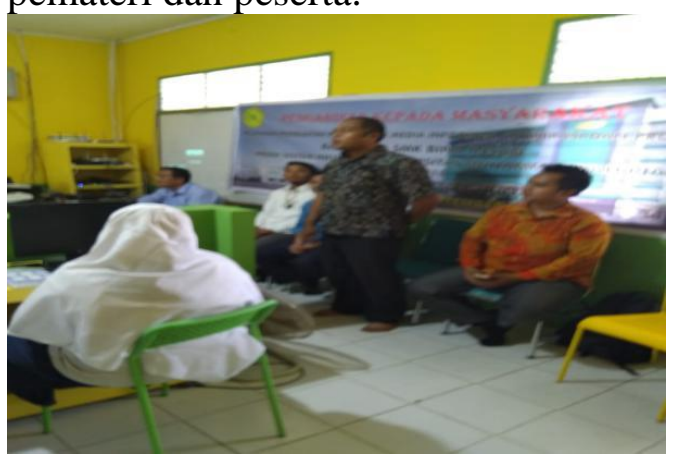

Gambar 6 Arahan dari Dekan Fakultas Ilmu Komputer

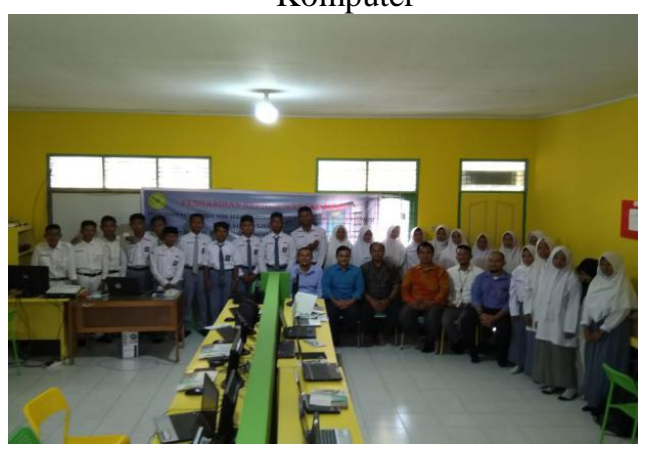

Gambar 7 Foto Bersama seluruh Pemateri dan peserta diakhir sesi

\section{SIMPULAN}

Dari kegiatan pengabdian yang telah dilaksanakan dapat disimpulkan bahwa pelatihan pembuatan web untuk sarana penyebaran informasi, publikasi dan promosi telah sukses dilaksanakan dan mendapatkan respon yang sangat baik dari para peserta.

\section{UCAPAN TERIMAKASIH}

$\begin{array}{ccc}\text { Ucapan } & \text { terimakasih diberikan } \\ \text { kepada } & \text { Rektor } & \text { Universitas }\end{array}$ Muhammadiyah Riau melalui Lembaga Pengabdian Pada Masyarakat (LPPM) UMRI,yang telah mensupport dalam bentuk moril maupun materi. Yayasan Bina Insan melalui Kepala Sekolah SMK Bina Insan yang telah memberikan izin pelaksanaan kegiatan pengabdian pada Prodi Sistem Informasi UMRI. Seluruh pemateri dan seluruh peserta yang talah mengikuti kegiatan pengabdian ini. Pihak terkait yang tidak disebutkan namun memiliki andil untuk mensukseskan kegitan pengabdian program studi Sistem Informasi, Fakultas Ilmu Komputer, Universitas Muhammadiyah Riau.

\section{DAFTAR PUSTAKA}

[1]. D. Winarso, E. Arribe, R. Diansyah, P. S. Informasi, F. I. Komputer, and U. M. Riau, "Pemanfaatan Internet Sehat Menuju," vol. 1, no. 1, pp. 19-23, 2017.

[2]. A. Nugroho, E-Commerce: Memahami Perdagangan Modern di Dunia Maya, II. Bandung: Informatika, 2006.

[3]. Anonim, "How Many Websites Are There Around the World?," www.millforbusiness.com, 2018. [Online]. Available: https://www.millforbusiness.com/howmany-websites-are-there/.

[4]. Anonim, "Web Server Survey," 2018. [Online]. Available: https://news.netcraft.com/archives/201 8/10/29/october-2018-web-serversurvey.html. 